\title{
Refractive outcome in eyes with retinopathy of prematurity treated with cryotherapy or diode laser: 3 year follow up
}

\author{
Donna M Knight-Nanan, Michael O’Keefe
}

\begin{abstract}
Aims-To compare the refractive error 1 to 3 years after cryotherapy or diode laser treatment for threshold retinopathy of prematurity.

Methods-Twenty six infants treated with diode laser and 17 infants treated with cryotherapy underwent cycloplegic refraction during follow up.

Results-After 3 years of follow up, $\mathbf{9 4 . 1 \%}$ of patients had myopia (right eye if bilateral) following cryotherapy and $45.5 \%$ of patients had myopia following diode laser treatment. The difference between the two proportions was $48.7 \%$ (95\% confidence interval 17.8 to $80.1, p=0.004)$. In the cryotherapy group $55 \%$ of patients were highly myopic ( $>-6.00$ dioptres) while in the laser group there were no high myopes.

Conclusions-In the diode laser group there were significantly fewer myopes than in the cryotherapy group up to 3 years after the procedure. There was no trend towards increasing myopia in the laser treated group and the refraction in these eyes stabilised after 1 year. In the cryotherapy group there was a significant increase in the degree of myopia between year 1 and year 3 of follow up $(p=0.02)$. Diode laser treatment is thought to be as effective as cryotherapy, and has the added benefit of reducing myopia, in the treatment of ROP.
\end{abstract}

(Brf Ophthalmol 1996;80:998-1001)

The high incidence of myopic refractive errors in premature infants is well known and has been previously reported. ${ }^{1-4}$ Myopia occurs more frequently with low birth weight, retinopathy of prematurity (ROP), and visual deprivation. In a previous study, ${ }^{5}$ we showed that after a 1 year period of follow up, eyes with threshold ROP treated with diode laser photocoagulation developed significantly less myopia than those treated with cryotherapy.

Both methods of treatment have been found The Children's Ireland D M Knight-Nanan M O'Keefe

Correspondence to: Mr Michael O'Keefe, The Children's Hospital, Temple Street, Dublin 1, Ireland.

Accepted for publication 23 August 1996 baby awake. The baby must be anaesthetised for cryotherapy to be carried out. Diode laser photocoagulation is delivered via an indirect binocular ophthalmoscope and therefore requires relatively clear media while cryotherapy to be equally effective in causing regression of the fibrovascular ridge, ${ }^{6-8}$ but the diode laser unit has the advantage of being portable and it can be used in the neonatal nursery with the can be carried out even with marked media opacities or an undilated pupil.

This longitudinal study evaluates the changes in refraction occurring over a 3 year period following treatment with either cryotherapy or diode laser photocoagulation with particular emphasis on whether or not the initial finding of a lower incidence of myopia in laser treated eyes is maintained during the follow up. The study includes the patients from the 1 year follow up study, as well as new cases treated since the time of the previous report.

\section{Materials and methods}

Children who were born prematurely attending the eye clinic at the Children's Hospital following treatment for threshold ROP with either cryotherapy or diode laser photocoagulation and who had been followed up for at least 1 year were selected for inclusion in the study. In this hospital, ROP reaching threshold was treated with cryotherapy in the period from September 1986 to November 1991, then the treatment was changed to laser ablation with a $810 \mathrm{~nm}$ wavelength diode laser from December 1991 to the present. Treatment was placed anterior to the fibrovascular ridge-that is, in avascular retina in all except two eyes in which treatment was placed both anterior and posterior to the ridge. Eyes which could not be refracted because of media opacities, such as cataracts, or because of detached retinas were excluded.

Eyes in which ROP had advanced beyond threshold (defined as stage 3 ROP in zones 1 or 2 for 5 contiguous or 8 cumulative clock hours of retina with plus disease) at the time of treatment were excluded.

Table 1 Spherical equivalents (SE) (dioptres) in cryotherapy group at 1, 2, and 3 years

\begin{tabular}{lccll}
\hline $\begin{array}{l}\text { Patient } \\
\text { No }\end{array}$ & $\begin{array}{l}\text { Eye } \\
\text { No }\end{array}$ & SE at 1 year & $S E$ at 2 years & $S E$ at 3 years \\
\hline 1 & 1 & -1.50 & -1.75 & -1.38 \\
2 & 2 & -8.00 & -8.00 & -9.00 \\
3 & 3 & -5.50 & -6.00 & -6.00 \\
4 & 4 & -5.00 & -5.00 & -8.00 \\
5 & 5 & +1.00 & +1.00 & +2.00 \\
6 & 6 & -8.00 & -8.00 & -9.00 \\
7 & 8 & -8.00 & -8.50 & -8.50 \\
8 & 9 & -3.00 & -2.75 & -3.25 \\
9 & 11 & -0.75 & -0.75 & -3.00 \\
10 & 12 & -4.25 & -6.00 & -5.50 \\
11 & 13 & -3.00 & -5.00 & -4.75 \\
12 & 15 & -2.00 & -2.00 & -2.75 \\
13 & 17 & -6.25 & -6.25 & -4.75 \\
14 & 19 & -4.00 & -4.00 & -3.75 \\
15 & 21 & -2.00 & -2.88 & -2.50 \\
16 & 23 & -6.00 & -8.00 & -8.00 \\
17 & 25 & +3.50 & +0.75 & -1.50 \\
\hline
\end{tabular}




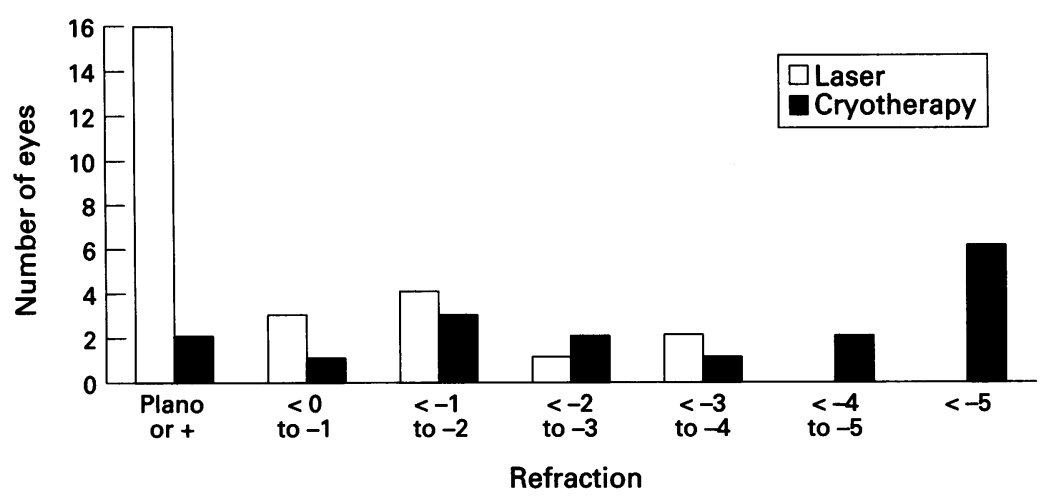

Figure 1 Refraction in laser $(n=26)$ and cryotherapy $(n=17)$ groups after 1 year.

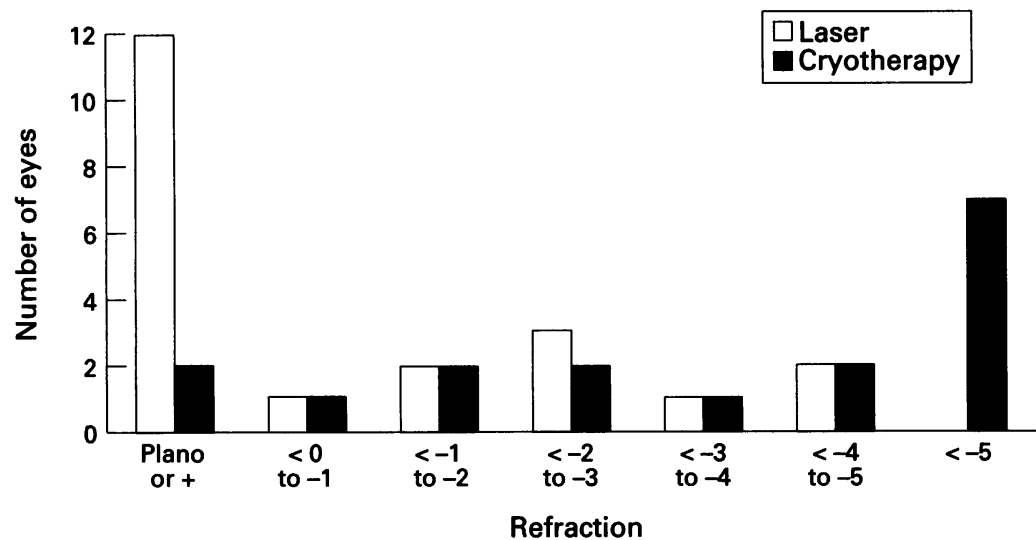

Figure 2 Refraction in laser $(n=21)$ and cryotherapy $(n=17)$ groups after 2 years.

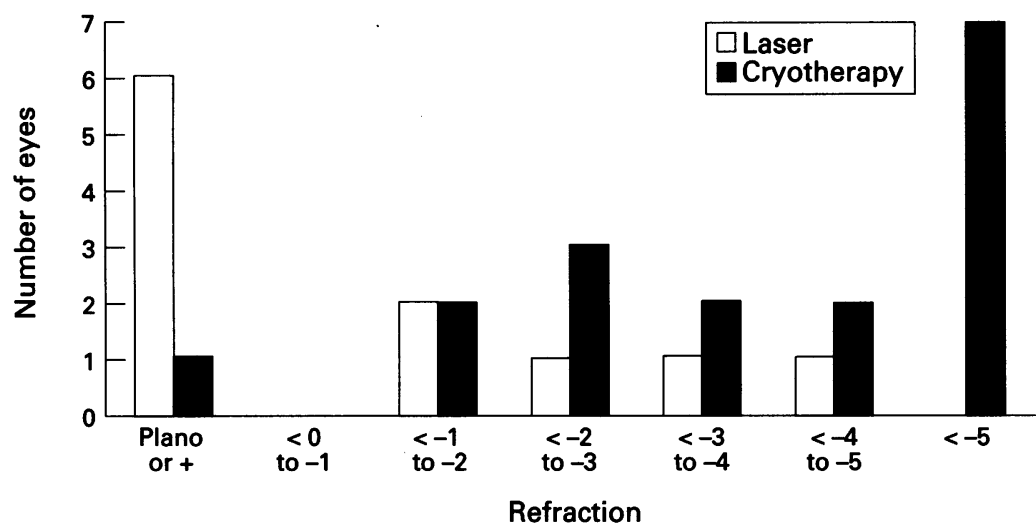

Figure 3 Refraction in laser $(n=11)$ and cryotherapy $(n=17)$ groups after 3 years.

There was no change in neonatal policy regarding oxygen therapy or other management during the period of the study.

The manual cycloplegic refraction at 1,2 , and 3 years was noted and entered into a database. In cases where treatment was bilateral the right eye was selected for inclusion in the study and all unilateral cases meeting the criteria outlined above were included. There were 17 eyes in the cryotherapy group and these were followed up for a mean of 5 years (range 4 to 9 years). The diode laser group comprised 26 eyes and the mean follow up was 2.5 years (range 1-4 years). Since not all eyes in the laser group had been followed up for at least 3 years, data were available on 21 eyes after 2 years and on 11 eyes after 3 years.

The gestational age in the diode laser group $(n=26)$ ranged from 24 to 32 weeks (mean 26.77 weeks), and in the cryotherapy group ( $\mathrm{n}$ $=17$ ) the gestational age ranged from 25 to 30
Table 2 Spherical equivalents (SE) (dioptres) in diode laser group at 1,2, and 3 years

\begin{tabular}{lllll}
\hline $\begin{array}{l}\text { Patient } \\
\text { No }\end{array}$ & Eye No & SE at 1 year & SE at 2 years & SE at 3 years \\
\hline 18 & 27 & -1.50 & -1.75 & -1.50 \\
19 & 28 & -0.63 & $\star$ & $\star$ \\
20 & 30 & +1.75 & +1.00 & +1.00 \\
21 & 32 & +2.50 & $\star$ & $\star$ \\
22 & 34 & -3.50 & -4.50 & -3.75 \\
23 & 36 & -1.63 & -3.00 & -2.00 \\
24 & 38 & +1.00 & +1.00 & +1.75 \\
25 & 40 & +1.00 & +1.00 & +2.00 \\
26 & 41 & Plano & Plano & Plano \\
27 & 42 & -3.13 & -4.25 & -4.88 \\
28 & 44 & -0.50 & -3.00 & -3.00 \\
29 & 46 & +2.13 & +2.25 & +2.00 \\
30 & 47 & +3.00 & +3.00 & +3.00 \\
31 & 48 & -3.00 & -3.50 & - \\
32 & 50 & -1.50 & -1.50 & - \\
33 & 52 & +2.75 & +2.50 & - \\
34 & 53 & Plano & Plano & - \\
35 & 55 & +1.00 & +0.50 & - \\
36 & 56 & +1.00 & +1.00 & - \\
37 & 58 & Plano & Plano & - \\
38 & 60 & +1.50 & - & - \\
39 & 61 & -1.00 & -3.00 & - \\
40 & 63 & -1.50 & -1.00 & - \\
41 & 65 & $\star$ & - & - \\
42 & 67 & +3.00 & - & - \\
43 & 69 & +1.00 & - & - \\
44 & 71 & +1.75 & - & - \\
\hline & & & & \\
\hline
\end{tabular}

^Incomplete data.

weeks (mean 26.79 weeks). The mean birth weight in the laser and cryotherapy groups was $918 \mathrm{~g} \mathrm{(660} \mathrm{to} 1500 \mathrm{~g})$ and $940 \mathrm{~g} \mathrm{(620} \mathrm{to} 1500$ g) respectively.

The proportions of patients with myopia in the cryotherapy and laser groups, the difference between the two proportions, and the 95\% confidence interval for this difference were given. The paired Student's $t$ test was used to test for the difference between the refraction at 3 years and the refraction at 1 year of follow up. All statistics were carried out with the EPI INFO Version 6.03 software package (Centers for Disease Control, Atlanta, Georgia).

\section{Results}

The refractive error in spherical equivalents at 1,2 , and 3 years of follow up in the laser and cryotherapy groups are shown in Tables 1 and 2 respectively. Table 3 shows the proportion of patients in each group with myopia, the difference between the two proportions and gives the $95 \%$ confidence interval. Figures 1,2 , and 3 compare the degree of refractive error between the laser and cryotherapy groups for the 3 years of follow up.

After 1 year of follow up the proportion of patients with myopia in the cryotherapy group was $88.2 \%$ and in the laser group $38.5 \%$ eyes were myopic. The difference between the two proportions was $49.8 \% \quad(95 \%$ confidence interval 25.6 to $74.0, p=0.001$ ). At 2 years the proportion of patients with myopia in the cryotherapy and laser groups was $88.2 \%$ and $42.9 \%$, respectively, and the difference between the proportions was $45.4 \%$ (95\% confidence interval 19.3 to $72.0, p=0.004)$. After 3 years of follow up $94.1 \%$ were myopic in the cryotherapy group and $45.5 \%$ were myopic in the laser group. The difference between the two proportions was $48.66 \%$ (95\% confidence interval 17.2 to $80.1, p=0.004)$. 
Table 3 Proportion of myopic patients in cryotherapy and diode laser groups; difference between the proportions and the $95 \%$ confidence interval (CI)

\begin{tabular}{llll}
\hline Year of follow up & $\begin{array}{l}\text { Cryotherapy group } \\
n(\%)\end{array}$ & $\begin{array}{l}\text { Diode laser group } \\
n(\%)\end{array}$ & Difference (95\% CI) \\
\hline 1 & $15 / 17(88.2)$ & $10 / 26(38.5)$ & $49.8 \%(25.6$ to 74$)$ \\
2 & $15 / 17(88.2)$ & $9 / 21(42.9)$ & $45.4 \%(19.3$ to 72$)$ \\
3 & $16 / 17(94)$ & $5 / 11(46)$ & $48.7 \%(17.8$ to 80.1$)$ \\
\hline
\end{tabular}

After 3 years of follow up, the highest myopic spherical equivalent in the cryotherapy group was -9.00 dioptres, and $94 \%$ of patients had myopia. The highest myopic spherical equivalent in the diode laser group was -4.88 dioptres. Fifty five per cent of patients in the cryotherapy group were highly myopic (greater than or equal to 6 dioptres of myopia). In the diode laser group $46 \%$ were myopic and there were no high myopes. Fifty five per cent of patients in the diode laser group were emmetropic or hypermetropic (plano to +3.00 dioptres) and $6 \%$ of patients in the cryotherapy group were hypermetropic (none was emmetropic).

The paired Student's $t$ test comparing year 1 and year 3 refraction showed that there was no significant increase in myopia in the diode laser group (mean difference -0.4 dioptres, $p=0.2$ ) while there was a significant increase in the degree of myopia in the cryotherapy group (mean difference -1.0 dioptres, $\mathrm{p}=0.02$ ).

No significant difference was found in the degree of astigmatism between the two groups.

\section{Discussion}

The association of myopia with retinopathy of prematurity is well known, and has previously been reported in the literature.$^{49}$ Myopia is also found more commonly in premature than in term infants, and the incidence is proportional to the degree of prematurity. ${ }^{310}$ In myopic premature babies without ROP, the myopia tends to decrease in degree during the first year of life. However, myopia tends to continue and to be greater in degree in infants with ROP, and there is a positive correlation between the degree of myopia and the severity of cicatricial ROP. ${ }^{39}$

One year after treatment of threshold ROP with either cryotherapy or diode laser photocoagulation, we found that eyes treated with diode laser developed significantly less myopia than those treated with cryotherapy. ${ }^{5}$ In this study published in 1994, the number of eyes in each group differed from the present study and both eyes of bilateral cases were included. The previous study found that $92 \%$ of eyes in the cryotherapy group $(n=25)$ were myopic $(-0.50 \mathrm{D}$ to $-8.00 \mathrm{D})$ while only $40 \%$ of eyes in the laser group $(n=15)$ were myopic $(-1.50$ $\mathrm{D}$ to $-3.50 \mathrm{D}$ ).

The findings of the present study show that 3 years after treatment $94 \%$ of patients in the cryotherapy group $(\mathrm{n}=17)$ were myopic $(-1.38 \mathrm{D}$ to $-9.00 \mathrm{D})$, and in the laser group $(n=11) 46 \%$ were myopic $(-1.50 \mathrm{D}$ to -4.88 D). In the cryotherapy group $55 \%$ were high myopes ( $>-6.00 \mathrm{D})$ while there were no high myopes in the laser group. During the 3 years of follow up there was no significant change in refraction in the laser group - that is, there was no trend towards increasing myopia. In the cryotherapy group however, there was a trend towards increasing myopia $(\mathrm{p}=0.02)$.

Various studies have pointed out that the optical basis of myopia associated with ROP is multifactorial, rather than due purely to increased axial length. ${ }^{10}$

Animal studies in the chick, rhesus and macaque monkeys, and tree shrew have demonstrated increased axial length as a result of visual deprivation. ${ }^{11-17}$ While this may not be applicable to human infants, an association between lid lesions and myopia has been shown. ${ }^{18}$

Neurochemical changes in levels of dopamine and vasoactive intestinal polypeptide have been demonstrated in eyes which have developed form deprivation myopia. ${ }^{1920}$ Apomorphine, a dopamine agonist, has been used to prevent the expected increase in axial length that occurs after form deprivation in the chick $^{2021}$ as well as the rhesus monkey. ${ }^{22}$

These neurochemical studies suggest that the retina and its metabolites are involved in the regulation of eye growth and refractive changes. Thus, the ablation of areas of peripheral retina could influence eye growth by decreasing the production of neurochemicals or growth factors which have an influence on eye growth. This could affect growth in both anterior and posterior segments of the eye thus effecting a change in corneal power, anterior chamber depth, lens power or axial length.

It is reasonable to postulate that the deep retinal burns produced by the $810 \mathrm{~nm}$ diode laser are very effective in reducing the production of chemical mediators of myopic change while causing little damage to adjacent areas of retina, choroid, and sclera. Cryotherapy produces larger areas of chorioretinal scarring than diode laser ablation and this should theoretically result in even greater reductions in chemical mediators and therefore less myopic change than laser treatment. It is possible that the relatively larger areas of chorioretinal adhesion and destruction of normal chorioretinal architecture with cryotherapy compared with diode laser ablation has a paradoxical effect by changing the structure of the sclera and making it more susceptible to stretching. Another possibility is that the large areas of destroyed choroid and retina may alter the production of other chemical mediators of eye growth, tipping the balance in favour of factors that cause corneal flattening or increased axial growth.

In future, it would be of interest to compare the refractive outcome of ROP treated with the argon green laser as opposed to the $810 \mathrm{~nm}$ diode laser to see whether the former, which penetrates less deeply into the retina, is also associated with a lower incidence of myopic refractive errors.

Previous studies have shown the diode laser to be equally as effective as cryotherapy in treating threshold ROP. However, high myopia is associated with an increased risk of amblyopia, retinal detachment, and myopic retinal degeneration. Therefore, the reduction of the 
degree of myopia in eyes treated for ROP will have a significant beneficial effect on the long term health and function of these eyes. This 3 year longitudinal study confirms the advantage of $810 \mathrm{~nm}$ diode laser over cryotherapy in reducing myopia.

We thank Dr Leslie Daly, of the Department of Public Health and Epidemiology, University College Dublin for help with statistical analysis.

1 Graham MV, Gray OP. Refraction of premature babies' eyes. $B M F$ 1963;1:1452-4

2 Shapiro A, Yanko L, Nawratzki I, Merin S. Refractive power of premature children at infancy and early childhood. Arch Ophthalmol 1963;69:166-73.

3 Nissenkorn I, Yassur Y, Mashkowski D, Sherf I, Ben-Sira I. Myopia in premature babies with and without retinopathy of prematurity. $B r f$ Ophthalmol 1983;67:170-3.

4 Gordon RA, Donzis PB. Refractive development of the human eye. Arch Ophthalmol 1985;103:785-9.

5 Algawi K, Goggin M, O'Keefe M. Refractive outcome following diode laser versus cryotherapy for eyes with retinopathy of

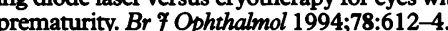

6 McNamara JA, Tasman W, Vander JF, Brown GC. Diode laser photocoagulation for retinopathy of prematurity. Preliminary results. Arch Ophthalmol 1992;110:1714-6.

7 Hunter DG, Repka MX. Diode laser for threshold retinopathy of prematurity-a randomised study. Ophthalmology 1993;100:238-44.

8 Goggin M, O'Keefe M. Diode laser for retinopathy of prematurity-early outcome. Br $\mathcal{F}$ Ophthalmol 1993;77: 559-62.

9 Quinn GE, Dobson V, Repka MX, Reynolds J, Kivlin J Development of myopia in infants with birth weight less than 1251 grams. The cryotherapy for retinopathy of prematurity cooperative group. Ophthalmology 1992;99: $329-40$.

10 Gordon RA, Donzis PB. Myopia associated with retinopathy of prematurity. Ophthalmology 1986;93:1593-8.

11 Smith III EL, Harwerth RS, Crawford MLJ, von Noorden GK. Observations on the effects of form deprivation on the refractive status on the monkey. Invest Ophthalmol Vis $S_{c i}$ 1987;28:1236-45.

12 Gottleib MD, Fugate-Wentzek LA, Wallman J. Different visual deprivations produce different ametropias and visual deprivations produce different ametropias and different

13 Yinon U. Myopia induction in animals following alteration of the visual input during development: a review. Curr Eye Res 1984;3:677-90.

14 Weisel TN, Raviola E. Myopia and eye enlargement afte neonatal lid fusion in monkeys. Nature 1977;266:66-8

15 von Noorden GK, Crawford ML. Lid closure and refractive error in macaque monkeys. Nature 1978;272:53-4.

16 Weisel TN, Raviola $E$. Increase in axial length of the macaque monkey eye after corneal opacification. Invest Ophthalmol Vis Sci 1979;18:1232-6.

17 Sherman SM, Norton TT, Casagrande VA. Myopia in the lid-sutured tree shrew (Tupaia glis). Brain Res 1977;124: lid-sutur.

18 Robb RM. Refractive errors associated with hemangiomas of the eyelids and orbit in infancy. Am $\mathcal{F}$ Ophthalmol 1977; 83:52-8.

19 Stone RA, Laties AM, Raviola E, Weisel TN. Increase in retinal vasoactive intestinal polypeptide after eyelid fusion in primates. Proc Natl Acad Sci USA 1988;85:257-60.

20 Stone RA, Lin T, Laties AM, Iuvone PM. Retinal dopamine and form-deprivation myopia. Proc Natl Acad Sci USA 1989;86:704-6.

21 Stone RA, L in T, Iuvone PM, Laties AM. Postnatal control of ocular growth: dopaminergic mechanisms. In: Myopia and the control of eye growth (Ciba Foundation Symposium and the control of eye growth (Ciba Foun

22 Iuvone PM, Tigges M, Stone RA, Lambert S, Laties AM Effects of apomorphine, a dopamine receptor agonist, on ocular refraction and axial elongation in a primate model of myopia. Invest Ophthalmol Vis Sci 1991;32:1674-7. 